\title{
Arte, Arquitectura, Comunicación y Ciudad: Interacciones y Diálogos
}

\author{
CARLOS PÉREZ REYES \\ PILAR AUMENTE RIVAS \\ Directores V Jornadas Internacionales Arte y Ciudad (2012)
}

La ciudad es el ámbito en el que se desarrollan actualmente las manifestaciones artísticas más reconocidas y relevantes. La urbe ha sido y continúa siendo en este sentido campo de actuación privilegiado, escenario mutante en que diversos y complejos factores ideológicos determinan o son influidos por las prácticas artísticas. Esta dialéctica entre arte y ciudad posee un enfoque poliédrico y con múltiples parámetros de atención, que estimulan un enfoque transversal y multidisciplinar al tema, tanto en el ámbito del diseño urbano como en el del arte público, la presencia de espacios para el arte o la iconografía urbana. Con este objetivo se han celebrado, ya en su quinta convocatoria, las Jornadas Internacionales Arte y Ciudad 2012 que anualmente organiza el Grupo de Investigación UCM Consolidado Arte, Arquitectura y Comunicación en la Ciudad Contemporánea, con la colaboración del Departamento de Comunicación Audiovisual y Publicidad II de la Universidad Complutense de Madrid.

El objetivo de esta plataforma ha sido vehicular, debatir y difundir las investigaciones que se vienen desarrollando en la actualidad sobre las múltiples interacciones entre el arte y la ciudad. Asumidas desde el inicio de la actividad del Grupo de Investigación con un carácter transversal, los estudios 
desarrollados dentro de esta línea de investigación se amparan en la comprensión de la ciudad como complejo entramado de relaciones sociales, artístico-culturales, económicas, políticas, etc., desarrolladas en un entorno urbano tanto más vital cuanto más rico en valores artísticos y patrimoniales, siguiendo en este sentido los planteamientos ya clásicos de Giulio Carlo Argan en torno a la idea de ciudad y los cada vez más consolidados "estudios culturales urbanos".

La pluralidad de intervenciones del arte creando ciudad y el análisis adecuado de las múltiples interacciones entre ambas, exigen una pluralidad de miradas que nos acerquen mejor a esa compleja riqueza. Para articular esta multiplicidad, las Jornadas se estructuraron en tres grandes secciones: Ciudad y Artes Plásticas; Ciudad y Comunicación; Ciudad, Arquitectura y Patrimonio. Cada una de estas secciones se organizó en niveles de ponencias y comunicaciones a través de las cuales se pudieran dar a conocer y debatir, sobre la base de un marco teórico apropiado en cada caso, las diferentes investigaciones que, en curso o ya finalizadas, vienen desarrollando los profesores e investigadores participantes. Uno de los puntos de reflexión ha sido la mirada hacia la ciudad en tanto sociedad, vivida por su población. Más allá de las repetidas y consagradas figuras "urbanas" con las que hemos venido construyendo infinidad de veces un a modo de skyline de la ciudad, lo que nos sigue faltando es un mayor conocimiento de su entramado vital, de ahí la importancia del estudio de la vida cotidiana, es decir, de la vida real de la ciudad en una faceta fundamental de su complejidad. En esa línea, se quiso llamar la atención sobre el interés que tiene el rastreo y estudio de aspectos que no han sido aún debidamente estimados en cuanto al papel que desempeñaron en determinados periodos, como son los Ateneos libertarios, los quioscos y ciertas instituciones culturales no oficiales que promovieron, impulsaron o difundieron la cultura, como planteó el hispanista Edward Baker en la conferencia inaugural, en la que se establecieron los puntos clave para la construcción de una historia cultural de Madrid en el primer tercio del siglo XX.

El valor de testimonio se atesora en los contenidos de las novelas populares que nos hacen conocer, con el pulso de la vida cotidiana, los espacios urbanos y los edificios que habitaron seres humanos con sus debilidades y pasiones; lo que permite apreciar la doble ciudad, la oficial, representada e investigada ampliamente, y aquella otra, de la que no se suele dar cuenta, 
pero absolutamente real. Ciudad recorrida por necesidades vitales que marcan una cartografía de lugares plenos de sentido que la ficción recoge y transmite como testimonio valioso para la memoria y que nos ayuda al mejor conocimiento y comprensión de la misma, como planteó Susan Larson en su ponencia. Comprensión que requiere del ahondamiento en las características que definen cada etapa del desarrollo histórico de la ciudad y que -en lo referente a la ciudad contemporánea-, como dejó apuntado el profesor Humberto Huergo, tiene una de sus armazones en la plasmación de la vertiente publicitaria materializada, desde el punto de vista visual, en la fuerte implantación del escaparate y el triunfo de la arquitectura comercial que define la presentación de la calle moderna.

Comprensión de la ciudad por medio de sus representaciones, del tipo y técnica que sean, puesto que esas interpretaciones no solo sirven al mantenimiento de la memoria de la ciudad, sino que yuxtaponen las posibles ciudades que cada artista, dibujante, pintor, fotógrafo o cineasta, ha podido añadir al mundo de lo real. Es tal el poder de estas imágenes que pueden, incluso, ejercer presión sobre los creadores de la ciudad que llegarían a subvertir valores en el proceso de creación arquitectónico-urbanístico, hasta el punto de plantearse realizar solo edificios y conjuntos urbanos que puedan convertirse en iconos con capacidad de convocar la representación, antes que la funcionalidad y propiedad de su existencia, aspecto en el que incidió la ponencia del escultor y arquitecto Juan Bordes. La importancia y el valor de las representaciones no debe hacernos olvidar, no obstante, que cualquiera que sea el lenguaje o técnica utilizada, siempre nos han otorgado una imagen amputada de la ciudad real. Ni la fotografía, ni la pintura, ni el dibujo, representan con autenticidad completa la ciudad; nos dan claves visuales, pero no sonoras; lo que sí nos aporta en cambio el cine sonoro, aunque no pueda transmitir claves olfativas que identificarían las ciudades en distintos periodos y culturas. No obstante, el gran interés de estas representaciones de la ciudad puede, como ocurre en el campo de la fotografía, dar la satisfacción de seguir descubriendo patrimonios olvidados o desconocidos que pese a su condición de imágenes sin "sentidos", de meras claves visuales, siguen aportando y enriqueciendo el conocimiento de los espacios urbanos precisamente en aquellos años de formación de los mismos en los orígenes de la ciudad contemporánea, como lo atestigua el fondo de fotografías J. Levy analizado por el profesor Hernández Latas. 
La ciudad, y por supuesto, la ciudad contemporánea, ha inspirado, de forma explícita o sugerente, representaciones poéticas, o críticas, en tanto generadora de placer o de rechazo; recordando que la ciudad puede ser incentivadora -cuando no causa directa- $y$, desde luego, escenario de la reivindicación. La canalización de esta energía crítica a través de proyectos de intervención artística, como el planteado por la profesora Isabel García en el Madrid de los últimos años del franquismo, ha propiciado, en ciertos casos coronados con el éxito -tras una intensa actividad- la generación de barrios consensuados que han mejorado las circunstancias de la población. En otras ocasiones esa energía artística puede ganar, para la ciudadanía que habita en los barrios faltos de ámbitos donde generar sueños y crecer en convivencia, espacios que transforman la desatención y dejadez edilicia en ámbitos para la vida y la belleza o para disfrute de lo lúdico-provechoso. Acciones que, además, pueden incentivar los aspectos identitarios de un barrio o pueden, incluso, llegar a transformarlos.

El arte y sus instituciones interactúan de otras muchas formas con la ciudad, siendo estímulo y fermento transformador del pensamiento y la formación de artistas que a su contacto crecen en sus posibilidades de aportación artística, como puso de manifiesto la profesora María Dolores Arroyo en su ponencia sobre los artistas canarios en Madrid; con la actividad de instituciones como los museos que, en su proceso de actualización, crean sinergias con su entorno, contribuyendo así a la recuperación de barrios y ciudades, como fue el caso planteado por la profesora Helena Barranha en el Chiado de Lisboa; con intervenciones de los artistas sobre el espacio público en actuaciones que pueden ir desde la apropiación estética del espacio urbano, por medio de expresiones artísticas como la danza, hasta las realizadas sobre barrios deprimidos o desatendidos, estimulando la convivencia, así como la reivindicación social y política, para lograr la mejora o la llamada de atención sobre quienes los habitan y sus condiciones de vida

Para saber quién se es y hacia dónde se va, hay que saber de dónde se viene, mantener la memoria. Hay que dedicar una importante atención a la conservación del Patrimonio, al estudio de los procesos de recuperación, socialización o musealización del patrimonio cultural, incluido el industrial. Importante en esa revisión es la consideración hacia determinadas técnicas, porque pueden transmitir claves políticas que debemos aprender a descifrar para comprender mejor 
el desarrollo y la evolución de las ciudades, es decir, aprender a valorar la piel que envuelve los edificios y ámbitos urbanos, ya que también esos recubrimientos son ciudad y portan las huellas de lo que se ha sido, e, incluso su desaparición, nos habla de lo que se es. Debemos interesarnos así mismo por los procesos de restauración de los bienes culturales y aprender a conocerlos no solo a través de la documentación, sino abriéndonos a los datos y señales que los restos nos dan in situ; conviene también atender a la posición del resto patrimonial, respecto al entorno, para descubrir las interrelaciones entre los edificios y el paisaje, sea urbano o natural; y así mismo analizar los sucesivos pasos de integración y reconversión de edificios y conjuntos patrimoniales, sabiendo realizar el paso del objeto aislado al entorno, incluso en el caso de conjuntos industriales comprendidos desde la perspectiva del paisaje cultural que entiende lo urbano en el entramado del territorio, como planteó la profesora Ángeles Layuno en la ponencia de clausura.

Las Jornadas desarrollaron muchos más puntos de interés girando en torno a las tres grandes secciones reseñadas. Cine, fotografía, arte urbano, paisaje, vanguardias, estética, arquitectura, restauración, centros históricos, iconografía, museos, centros de arte, barrios artísticos...., fueron enriqueciendo el panorama interdisciplinar con que siempre se plantearon estas jornadas en las diferentes comunicaciones presentadas, de las que la presente monografía, número extraordinario de la revista de investigación Arte y Ciudad, quiere dejar constancia. Todas ellas deberían actuar como fermento de actividad constante que inste a seguir investigando, a saber más del objeto de estudio, sobre el que, al hilo de esta plataforma, se hayan podido abrir nuevas perspectivas.

Una breve enumeración de las conclusiones a las que se ha podido llegar tras estos intensos días de debate y reflexión nos llevaría a destacar, como puntos de especial interés sobre los que poder ahondar en próximas convocatorias, los siguientes aspectos:

- Existe una creciente necesidad de armonización y coexistencia de los estudios que analizan las evoluciones de los grandes conjuntos urbanos, abordados desde un planteamiento comprensivo, extenso e integrador que desarrolle las grandes líneas de transformación de las metrópolis y megalópolis, junto a la especial atención que debe prestarse a la lectura 
de las relaciones de la ciudad con quienes la habitan, los usos sociales del espacio urbano, en el marco de los cada vez más consolidados estudios culturales urbanos.

- Es fundamental también destacar la importancia de las investigaciones sobre los contextos territoriales, insistiendo en el interés fundamental de analizar el paso del estudio del objeto urbano concreto y aislado, al acercamiento de los entornos inmediatos y a la investigación de los grandes conjuntos en su relación con el territorio, profundizando así en la orientación desarrollada por los estudios de los paisajes culturales.

- Conveniencia de insistir en la necesaria profundización en los estudios de las representaciones de la ciudad en la línea de la lectura de la ciudad soñada o asumida críticamente, siendo conscientes de las limitaciones o especificaciones del medio expresivo utilizado, y estimando sus aportaciones en cada caso.

- Incentivación del acercamiento a los procesos de restauración, interpretación, recuperación y gestión del patrimonio cultural, con sensibilidad hacia estos procesos que sirvan tanto para la conservación de la identidad de las ciudades, como para la evaluación, oportunidad y adecuación de las refuncionalizaciones del mismo.

- Valoración de las intervenciones directas de los artistas en el medio urbano, ya sea con carácter efímero, ya permanente, y con pretensiones estéticas o críticas y reivindicativas, en sintonía con las aproximaciones desde el enfoque de la esfera pública y de la cultura como agente activo de lo urbano.

- Desarrollo de investigaciones encaminadas a la recuperación y valoración del papel que los barrios artísticos han tenido y tienen en el desarrollo de la ciudad contemporánea, tanto en el ámbito social como cultural y artístico, atendiendo también aquellos casos que, desde el barrio hacen la transición al estudio de lo que podemos denominar Distrito Cultural. La denominación de "barrio artístico" es una construcción cultural que se ha desarrollado en la literatura y en las artes hasta convertirse en un concepto habitual para designar una alta concentración de presencias artísticas entre las que cabe destacar cuatro factores funda- 
mentales: su representación por los artistas o evocación por la literatura, el cine, la fotografía o la música; la afluencia de artistas en la calle, en los talleres, en los cafés y en los locales de ocio; la abundancia de arte en el espacio público, desde murales, esculturas y monumentos, a instalaciones multimedia, mobiliario urbano, performance o arquitecturas; y la profusión de establecimientos artísticos tales como academias, escuelas de arte, museos, galerías de marchantes o fundaciones.

- Importancia de la elaboración de estrategias que permitan la creación y/o ampliación de redes de intercambio de investigaciones y de establecimiento de proyectos conjuntos de nivel internacional.

- Estimulación y apoyo al desarrollo de plataformas de intercambio y difusión que permitan y faciliten el libre acceso al conocimiento y no únicamente como complemento de las redes creadas.

Volviendo al planteamiento inicial, la Jornadas Internacionales Arte y Ciudad 2012 han tratado de revelar, desde una mirada crítica en diversas ciudades y en diferentes momentos, las poéticas urbanas que surgen de la interrelación entre una amplia gama de comportamientos asociados a la producción, gestión y difusión de actividades artísticas en el marco de la ciudad, con especial atención al contexto contemporáneo. El objetivo prioritario fue constituir una plataforma de reflexión y debate desde todos los sectores implicados, cuyo resultado, entendemos que altamente positivo, queda reflejado en las ponencias y comunicaciones presentadas entonces, y recogidas ahora en el presente volumen.

Desde aquí, nuestro agradecimiento a la Decana de la Facultad de Ciencias de la Información, María del Carmen Pérez de Armiñán, al Secretario de la Facultad de Geografía e Historia, Jesús Gutiérrez Burón y a la Directora del Departamento de Comunicación Audiovisual y Publicidad II, María José Canel Crespo por su apoyo y participación en la inauguración de las Jornadas, así como a cuantos ponentes y comunicantes pasaron aquellos días por las diferentes sesiones. Al profesor e hispanista Edward Baker, a quien acompañaron como ponentes durante los tres días los también hispanistas Susan Larson y Humberto Huergo, a la directora del Museo de Arte Contemporáneo de Lisboa Helena Barranha, al escultor y arquitecto Juan Bordes y a los 
profesores Javier Pérez Segura, María Dolores Arroyo Fernández, Ángeles Layuno Rosas, Isabel García García y José Antonio Hernández Latas. No queremos dejar de hacer una mención a la impecable labor del coordinador de las Jornadas, el profesor Miguel Ángel Chaves Martín, al que queremos agradecer su gran y eficaz dedicación, así como al equipo técnico y de organización: Jennifer García, Olga Heredero, Estíbaliz Pérez, María José Velasco, Ángel Sancho, Sergio Escudero y Daniel Sancho por su excelente trabajo.

El éxito de la convocatoria se puso también de manifiesto en el nivel y el número de comunicaciones presentadas, más de cincuenta, de las que el Comité Científico hizo una selección para su presentación pública en las diferentes sesiones desarrolladas, valorando especialmente la diversidad y calidad de los autores, procedentes de Universidades y Grupos de Investigación de Madrid, Málaga, Oviedo, Zaragoza, Alcalá de Henares, Castellón, Valladolid, Segovia, Cuenca, Santiago de Chile, México D.F. y Guadalajara (México), Belo Horizonte (Brasil), Florida y Minnesota (U.S.A.).

A todos ellos, nuestro más sincero agradecimiento.

CARLOS PÉREZ REYES

PILAR AUMENTE RIVAS

Directores V Jornadas Internacionales Arte y Ciudad 